\title{
Confissões de adolescentes: os olhares da adolescência na escola
}

\author{
Paulo de Tarso Xavier Sousa Junior ${ }^{1}$ \\ Hélvia Moreira Mineiro Martins²
}

\begin{abstract}
Resumo
Este projeto foi realizado com adolescentes do $9^{\circ}$ ano do Ensino Fundamental de instituições de ensino da cidade de Teresina-PI com o objetivo de analisar como os adolescentes percebem a escola e quais perspectivas apresentam sobre seu futuro acadêmico. O método utilizado foram técnicas de dinâmicas de grupo, com a finalidade de obter qual a visão desses adolescentes sobre a escola. Conclui-se que os alunos possuem uma visão muito distorcida da escola, uma vez que os profissionais que atuam nela apresentam dificuldades em repassar seu papel. Os adolescentes também ressaltaram a interferência de outros fatores no seu comportamento e desempenho. Palavras-chave: Adolescência; Escola; Relato de experiência.
\end{abstract}

\section{Confessions of adolescents: the adolescent looks at school}

\section{Abstract}

This project was carried out with adolescents from the 9th grade of elementary education at Teresina-PI, with the objective of analyzing how adolescents perceive the school and what perspectives they present about their academic future. The method used was group dynamics techniques, in order to obtain the vision of these adolescents about the school. We conclude that the students have a very distorted view of the school, since the professionals who work in it have difficulties in passing on their role. The adolescents also emphasized the interference of other factors in their behavior and performance.

Keywords: Adolescence; School; Experience report.

\section{Introdução}

O ciclo do desenvolvimento humano é composto por várias fases, começando desde o momento em que o embrião é gerado pela mulher ao longo de nove meses e, então um novo ser vivo chega ao mundo passando por fases como a infância, adolescência, adultez e por fim a velhice.

A adolescência tem sido definida pela Organização Mundial de Saúde (OMS, 1965 apud SCHOEN-FERREIRA; AZNAR-FARIAS; SILVARES, 2010) como um período biológico, psicológico e social compreendido entre os 10 aos 20 anos, mas nem todas as entidades se utilizam desse critério; por exemplo, o art. $2^{\circ}$ do Estatuto da Criança e do Adolescente, considera para efeitos

\footnotetext{
${ }^{1}$ Facid/Wyden. Teresina/PI. Endereço eletrônico: paulo_juniorpio@hotmail.com

${ }^{2}$ Facid/Wyden. Teresina/PI. Endereço eletrônico: helviampsi@hotmail.com
}

\section{Periódico Horizontes - USF - Itatiba, SP-Brasil - e019010}


desta lei o adolescente como um ser entre doze e dezoito anos de idade (BRASIL, 2013).

Em meio a tantas definições de critérios, os autores e os órgãos concordam que a adolescência é uma fase de constante mudança, inclusive corporais conhecida como puberdade, e que é influenciada por vários fatores como o cultural. Dos seres vivos, os humanos são os únicos que experienciam a adolescência, na maioria das culturas, como uma etapa importante em seu desenvolvimento, porém passar por essa mudança não é nada fácil. Além do aparecimento das primeiras mudanças físicas - conhecida como puberdade - que nascem independentes da vontade do indivíduo, nem da família a não ser por medicação (TIBA, 1986). O adolescente precisa lidar com as frustrações, os limites e colocar em prática ações que transformem seus sonhos em realidade (CONTINI, 2002).

Uma grande parcela da população brasileira corresponde a indivíduos que se encontram nessa fase do desenvolvimento humano, aproximadamente 45 milhões de brasileiros possuem entre 10 a 19 anos (BRASIL, 2010), e a mesma oferece várias oportunidades para o crescimento em vários termos, mas também uma fase repleta de riscos para o seu bem-estar físico e mental, fazendo com que a psicologia do desenvolvimento interfira promovendo ações para reverter esse último quadro (PAPALIA; FELDMAN, 2013).

Estudar o desenvolvimento humano, portanto significa conhecer as características comuns de uma faixa etária, permitindo nos reconhecer individualidades, o que nos torna mais aptos para observação e interpretação dos comportamentos (PAPALIA; FELDMAN, 2013).

A escola é um lugar protagonizado por indivíduos que estão passando pelo período do desenvolvimento humano conhecido como adolescência, cumprindo o papel de preparar para a vida adulta, além de aprenderem a trabalhar, assimilar regras sociais, conhecimentos básicos, valores morais coletivos e modelos de comportamentos considerados adequados pela sociedade (BOCK; FURTADO; TEIXEIRA, 2008). Além disso, a preparação da escola para o futuro do indivíduo faz com que a mesma se torne um lugar de grande influência positiva na vida humana.

Diante disso, surgiu o projeto "Confissões de Adolescentes" com o intuito de abordar e discutir com os alunos de três escolas da cidade de Teresina/PI algumas questões como: Quais as visões dos adolescentes a respeito da escola? Quais são os conflitos e dificuldades presentes no cotidiano escolar dos adolescentes? Quais os aspectos positivos da escola que podem ser 
apresentados para os adolescentes? Qual a relação entre a escola e o adolescente?

O objetivo geral deste projeto foi analisar como os adolescentes percebem a escola e quais perspectivas apresentam sobre seu futuro acadêmico. Para tanto, como objetivos específicos foram enunciados: identificar os conflitos e dificuldades presentes do cotidiano escolar dos adolescentes e estimular a reflexão sobre a relação do adolescente e da escola, utilizando técnicas vivenciais.

\section{Adolescências: o tornar-se jovem}

Segundo Tiba (1986), a palavra adolescente origina do latim adolescere, significando crescer, engrossar, tornar-se maior ou atingir a maioridade. Na obra de Bock, Furtado e Teixeira (2008) apresentam o psicanalista Erik H. Erikson como o responsável por formalizar o conceito de adolescência após a ideia de moratória social, que trata de um período no qual o indivíduo passava pela necessidade de estabelecer uma identidade, já que isso marcava uma fase de contradições, confuso, ambivalente e às vezes bastante doloroso, segundo Aberastury e Knobel (1981). Portanto seria uma transição do desenvolvimento humano entre a infância e a vida adulta impondo mudanças físicas, cognitivas e psicossociais (PAPALIA; FELDMAN, 2013).

Cada sociedade parece lidar com a adolescência de uma forma diferente, porém o que a marca o seu início em muitas culturas é através da puberdade, deflagrados não somente como impulsos biológicos causando grandes transformações no corpo, como também um sinalizador de escolhas e construções sociais para a vida adulta (LíRIO, 2012).

A forma como a adolescência era vista foi sendo modificada ao longo dos séculos. $\mathrm{Na}$ Antiguidade, a fase anterior em que o indivíduo passava a ter as responsabilidades de um adulto era julgado por um momento crítico devido a ser avesso aos bons costumes e incapaz de escolher o bem sem o conselho dos mais velhos (LÍRIO, 2012). De acordo com Schoen-Ferreira, AznarFarias e Silvares (2010), na Grécia Antiga, a partir dos 15 anos, os jovens já se casavam além de uma preparação desses jovens que era exclusiva por sexo, os homens escolhiam entre a guerra e a política já às mulheres a maternidade, já no início do Império Romano os pais eram os responsáveis para ensinar aos mais jovens uma educação na qual se tornava um agricultor, 
cidadão ou guerreiro e o casamento se consumava no máximo aos 14 anos, se tornando uma pessoa adulta.

Durante a Idade Média, aos primeiros sinais visíveis de mudanças no corpo, havia a troca das vestes da criança ou do adolescente para a de um adulto, além de passarem um período na casa de profissional para aprenderem boas maneiras e preparação para assumir a função relativa à sua classe social (LÍRIO, 2012).

Bock, Furtado e Teixeira (2008) mencionam que durante a sociedade pré-industrial, as crianças tornavam-se adultas por conta do ambiente familiar já que as mesmas aprendiam o ofício dos pais, porém com a chegada da Revolução Industrial as fábricas passaram a abrigar funcionários exclusivamente adultos e Contini (2002) relata que os pais queriam ter seus filhos mais tempo em sua tutela sem a necessidade de trabalhar, portanto mantê-las na escola foi uma solução. Já nos dias atuais, com a chegada de novos avanços tecnológicos, Aberastury e Knobel (1981) citam que o adolescente sente que é o maior responsável por planejar a sua vida, controlar as mudanças nos quais ele irá passar e assim se adaptar ou não gerando reformas sociais.

Dos seres vivos, os humanos são os únicos que experienciam a adolescência, na maioria das culturas, como uma etapa importante em seu desenvolvimento, porém passar por essa mudança não é nada fácil. Além do aparecimento das primeiras mudanças físicas - conhecida como puberdade - que nascem independentes da vontade do indivíduo, nem da família a não ser por medicação, conforme Tiba (1986). O adolescente precisa lidar com as frustrações, os limites e colocar em prática ações que transformem seus sonhos em realidade (CONTINI, 2002).

Portanto, a adolescência envolve uma série de significados que se faz necessário um olhar diferenciado para compreender a complexidade desse ciclo de vida, já que segundo o BRASIL (2010) aproximadamente 45 milhões de brasileiros possuem entre 10 a 19 anos. Entretanto, segundo Bock, Furtado e Teixeira (2008) leituras feitas pela Psicologia Sócio Histórica, retratam a adolescência como uma construção da modernidade e relata as necessidades e regras impostas da sociedade para esses jovens. Em contrapartida, Rappaport; Fiorri e Davis (1981-1982) relata que esses jovens repensam nos mistérios e problemas que surgem e lutam bravamente para achar uma resposta adequada a eles, questionando sempre a si próprio e em busca de um papel para si mesmo.

Periódico Horizontes - USF - Itatiba, SP-Brasil - e019010 
Além disso, o adolescente passa a enfrentar a difícil tarefa de evitar qualquer contato com o mundo dos adultos ao mesmo tempo em que ele se vê como igual e que superou sua infância, pois essa percepção o faz a mostrar constantemente sua individualidade, seus planos e desejos para o futuro (RAPPAPORT; FIORRI; DAVIS, 1981-1982).

Ninguém pode negar que a adolescência recebe o auxílio diretamente de vários fatores que ajudam em sua construção como é citado na obra de Aberastury e Knobel (1981) como: a busca de si mesmo e da identidade, tendência grupal, crises religiosas, necessidade de intelectualizar e fantasiar, evolução sexual e dentre outros - nas quais as autoras denominaram de "síndrome normal da adolescência" -, mas destacamos aqui um lugar de fundamental importância na vida do adolescente: a escola.

\section{A escola como instituição social}

Se consultarmos o dicionário encontraremos a definição da palavra escola como "sf. 1. Estabelecimento público ou privado onde se ministra ensino coletivo" (FERREIRA, 2001, p. 281), porém essa criação social do homem não se desenvolveu da noite para o dia.

Bock, Furtado e Teixeira (2008) esclarecem que foi na Idade Média que a educação se tornou produto da escola. Pessoas especializaram-se na tarefa de transmitir o saber, lecionando os valores da cultura aristocrata e os conhecimentos religiosos, em locais específicos para essa atividade. Poucos iam à escola, já que a mesma era destinada às elites. Os alunos eram os filhos das famílias mais ricas e poderosas da época na qual passaram nobres e burgueses aos nobres. Os conteúdos em sala de aula faziam da mesma um lugar para se ensinar a guerra, o saber intelectual ou um simplesmente aprendizado religioso.

O desenvolvimento da industrialização durante os séculos XIX e XX apresenta como uma efetiva transformação do âmbito escolar para o que conhecemos na atualidade. A escola passou por transformações, sendo a principal delas a universalização, ou seja, a partir de agora ela passaria a atender todas as crianças e adolescentes independentes da classe social, contudo, esse feito só se deu devido às manifestações feitas pelas classes de trabalhadores que exigiam melhores condições para seus filhos além de terem um lugar digno para o aprendizado, portanto

Periódico Horizontes - USF - Itatiba, SP-Brasil - e019010 
a instituição não teve outra saída a não ser receber toda essa nova classe de alunos a fim de se tornarem cidadãos capazes de planejar seu futuro (BOCK; FURTADO; TEIXEIRA, 2008).

O jeito de lecionar também foi sofrendo alterações, pois a escola não somente passava a ensinar o indivíduo para o trabalho como também a oferecer conhecimentos básicos da língua e do cálculo. Hoje encontramos uma realidade muito distinta, a escola cresceu e atualmente não apresenta somente matérias como geografia, química ou física, mas ela vai, além disso, instruem o indivíduo a crescer, alterando assim seus valores, comportamentos e assimilar regras de convivência em nossa sociedade (BOCK; FURTADO; TEIXEIRA, 2008).

Segundo Brasil (2009), existe aproximadamente no Brasil 52.580 .452 estudantes na Educação Básica, que compreende a Educação Infantil (creche e pré-escola), o Ensino Fundamental (1o a 9o ano ou 1a a 8a série), o Ensino Médio, a Educação Profissional, a Educação Especial e a Educação de Jovens e Adultos (nas etapas Ensino Fundamental e Ensino Médio) somando isso a um total de 197.468 escolas públicas. Do total de matriculados, 45.270 .710 estão em escolas públicas $(86,1 \%)$ e 7.309 .742 estudam em escolas da rede privada $(13,9 \%)$.

A escola acima de tudo forma cidadãos, deixando não somente a didática das matérias como alvo, mas também onde as relações sociais possam ser questionadas além da formação de indivíduos conscientes de sua inserção social (LANE, 1981). O que ocorre quando a relação adolescência e escola entram em conflito? A psicologia pode entrar como um meio de resolução da crise desse conflito.

\section{O diálogo da psicologia com o jovem e a escola}

Conforme Patto (1997), a definição de que o papel do psicólogo na escola é aperfeiçoar a qualidade do nível educacional dos alunos utilizando assim conhecimentos psicológicos chega a ser algo ambíguo, pois não há a preocupação outros fatores como: O que é ensino eficiente? Quais estratégias para definir isso? O psicólogo deve escutar as diversas demandas que surgem na escola e pensar em estratégias para lidar com tais questões (ANDRADA, 2005).

Classes numerosas, baixa remuneração, dificuldades generalizadas com a clientela como indisciplina e aprendizagem têm sido um dos principais problemas apontados pelos professores 
em sala de aula (KHOURI, 1984). Porém, o psicólogo deve estar atento para não eleger um modelo que explique os movimentos de indisciplina e aprendizagem, pois é necessário ter uma percepção integrada acerca de situações que possam impactar negativamente no processo de ensino e aprendizagem observado no espaço escolar e possíveis soluções (ANDRADA, 2005).

A preparação para um futuro profissional e aprender a conviver em sociedade através de suas normas faz parte da educação do aluno em sala de aula, portanto o papel da escola se faz essencial na vida do adolescente. Segundo Dayrell (2009) no cotidiano das escolas, o jovem geralmente aparece como problema, com ênfase na sua disciplina; na sua "falta de respeito", na sua "irresponsabilidade" diante dos compromissos escolares; na sua "rebeldia" quanto à forma de se vestir - o que pode gerar motivo de um conflito já que a maioria das escolas exige um padrão rígido de vestimenta. Diante disso se faz necessário como acentua Khouri (1984) o psicólogo atuar como parte de um grupo no qual está a serviço de transformar cada vez mais a educação, pois é necessária uma escuta dos alunos assim como dos profissionais da escola, além da presença da família para que assim essas barreiras existentes contra os adolescentes sejam quebradas.

De acordo com Clerget (2004), outro ponto importante são as dificuldades escolares, um dos motivos mais comuns nos consultórios de psicologia. Os pais se preocupam com o futuro profissional dos filhos, já que o desemprego atinge principalmente aqueles que não possuem um nível de escolaridade aceitável. A pressão escolar, a competitividade, o futuro profissional incerto e até mesmo o desinteresse de alguns pais no desempenho escolar dos seus filhos são alguns dilemas encontrados nos adolescentes.

A teoria da inteligência múltipla criada por Gardner nos leva a compreender que existe uma variedade de inteligências no indivíduo que trabalham juntas, a fim de fazer com que cada um desenvolva habilidades diversas (ATKINSON \& HILGARD, 2012). Portanto, o psicólogo ajuda a disseminar a ideia de que não se deve impor aos adolescentes o sucesso em todos os campos escolares e ao mesmo tempo, pois o saber não é independente da evolução psicoafetiva e os investimentos se repartem de maneira heterogênea por diferentes matérias (CLERGET, 2004).

Dayrell (2009) afirma que além de conhecermos o ambiente escolar é necessário estar atento às demandas desses adolescentes e necessário um olhar antropológico para nos dirigir para a realidade que esses jovens enfrentam fora dos muros da escola, para assim conhecê-los 
melhor. O psicólogo estará construindo caminhos junto com a escola atendendo de uma forma melhor as necessidades reais dos jovens (KHOURI, 1984).

O período escolar, agora bem mais extenso - no Brasil, por exemplo, foi recentemente adicionado mais um ano à grade escolar - gera atualmente novos conflitos para os adolescentes, como o distanciamento dos pais, que precisam passar muito tempo trabalhando, em vários casos com dois ou mais empregos e consequentemente se distanciamento da família, aproximando os adolescentes de outras pessoas do seu seio familiar e até mesmo chegando a formar grupos de iguais refletindo assim não só no desempenho do adolescente, mas na sua maneira de ver a escola (HABIGZANG; DINIZ; KOLLER, 2014). Fica bastante claro o papel do psicólogo escolar no qual colabora com esses jovens que precisam de alguma atuação específica (KHOURI, 1984).

\section{Material e métodos}

O projeto foi realizado em duas escolas da rede pública, sendo do sistema municipal e outra do sistema estadual, e uma da rede privada da cidade de Teresina/PI, onde foram realizados encontros nessas instituições com alunos do sexo masculino e feminino das turmas do $9^{\circ}$ ano do ensino fundamental, com a faixa etária entre 14 a 16 anos totalizando a participação de 109 alunos ao todo. Os encontros nas escolas duraram aproximadamente 60 minutos e foram realizadas duas pelo turno da manhã e uma à tarde.

Durante os encontros nas escolas com esses adolescentes, foram abordadas dinâmicas de integrativas e reflexivas para criar uma interação entre os alunos, podendo assim, escutar seus pensamentos e crenças sobre a escola, além da apresentação de um diário virtual, um blog para que os mesmos utilizassem dessa tecnologia para exporem sua rotina no cotidiano escolar e discussão de temas relacionados a esta questão.

\section{Dinâmicas feitas nos encontros realizados nas escolas}

- Momento de Apresentação e Descontração: Dinâmica do Papel Materiais: pedaço de papel, caneta. 
Procedimento: Forma-se um círculo e, em seguida será distribuído um pedaço de papel para cada um e com uma caneta o participante deverá escrever uma pergunta que quiser (Ex: Por que de manhã faz sol?). Logo em seguida o instrutor irá recolher o papel de todos os participantes, embaralhar e entregar novamente para os participantes. Cada um, então, deverá responder à pergunta que contém no papel que recebeu. Novamente o instrutor da dinâmica recolhe os papéis, os embaralha e os redistribui para os participantes. Uma pessoa começa lendo a pergunta que está no seu papel, em seguida a pessoa que está a sua direita irá responder à pergunta com a resposta que está escrita no seu papel e assim segue até que todos tenham falado causando muita risada e diversão.

- $\quad$ O que eu penso da escola?

Materiais: papel cartão, pincel.

Procedimento: Cinco alunos são convidados para que eles escrevam em uma palavra o que eles pensam da escola. Após escrever a palavra, cada um deverá explicar a escolha da sua palavra e os demais alunos poderão comentar se concordam ou discordam colocando seu ponto de vista e estabelecendo assim um diálogo inicial.

- $\quad$ Conta pra gente a verdade!

Materiais: garrafa, envelopes.

Procedimento: Os alunos formam um círculo com aproximadamente quatro pessoas e escolherão um envelope com números de 1 a 9. Dentro desses envelopes existem temas que estão relacionados com a escola como relacionamento, família, amigos, professores e etc. Um aluno gira a garrafa e para quem a garrafa irá apontar deverá responder a pergunta sobre o tema do envelope. A dinâmica irá relacionar temas externos que possuem ligação direta com a escola.

- $\quad$ Profissões com objetos

Materiais: figuras diversas.

Procedimento: Serão apresentadas aos alunos algumas figuras de objetos no centro do círculo. Eles deverão se aproximar do centro e escolher um objeto que the agrade e explicar o motivo da escolha. Os instrutores, em seguida, dirão que cada objeto representa uma profissão e assim iniciar outro diálogo com os alunos sobre o que eles esperam da vida após a escola e quais caminhos profissionais escolher.

Periódico Horizontes - USF - Itatiba, SP-Brasil - e019010 
- Momentos doces e amargos:

Materiais: folha de depoimento personalizada

Procedimento: Será entregue uma folha para os adolescentes que quiserem participar pedindo para que em algumas linhas relatem algo que aconteceu ou está acontecendo em seu ambiente escolar, podendo ser doces ou amargos.

Após a finalização das dinâmicas foi entregue uma folha para os adolescentes que quisessem participar, pedindo para que em algumas linhas relatassem algo que aconteceu ou está acontecendo em seu ambiente escolar, podendo ser doces ou amargos, deixando claro que não havia necessidade de colocar alguma identificação sobre quem estava escrevendo. Os depoimentos desses jovens foram colhidos e anexados para a produção de um diário escolar.

\section{Resultados e discussão}

Ao nos deparamos com as atividades de campo, encontramos tantas realidades distintas, mas com algo em comum: a apatia dos alunos. Durante os encontros nas escolas da rede pública, as estruturas da mesma foram duramente criticadas pelos alunos, pois muitos não gostavam do lugar onde estudam, já que as condições não eram muito apropriadas.

De acordo com Clerget (2004), um ponto importante a se ressaltar são as dificuldades escolares. Os pais se preocupam com o futuro profissional dos filhos, já que o desemprego atinge principalmente aqueles que não possuem um nível de escolaridade aceitável. A pressão escolar, a competitividade, o futuro profissional incerto e até mesmo o desinteresse de alguns pais no desempenho escolar dos seus filhos são alguns dilemas encontrados nos adolescentes. Os alunos citaram que apesar do esforço e da ânsia pelo aprendizado alguns fatores externos influenciavam diretamente em seu comportamento em sala de aula, como a falta de atenção dos pais já que muitos relataram que seus pais não acompanham sua vida escolar por vários motivos: desinteresse, falta de tempo, distância e outros.

A teoria da inteligência múltipla, criada por Gardner, nos leva a compreender que existe uma variedade de inteligências no indivíduo que trabalham juntas a fim de fazer com que cada um desenvolva habilidades diversas (ATKINSON \& HILGARD, 2012), porém os adolescentes

Periódico Horizontes - USF - Itatiba, SP-Brasil - e019010 
relatavam em seus discursos a cobrança para o sucesso em todas as áreas escolares para a construção de um bom futuro. O foco é que não se deve impor aos adolescentes o sucesso em todos os campos escolares e ao mesmo tempo (CLERGET, 2004).

Os professores também não ficaram de fora do discurso dos alunos. A indisciplina e o desinteresse dos alunos foram pontos citados por esses profissionais durante conversas informais antes da realização dos encontros. Conforme Habigzang, Diniz e Koller (2014), a maioria dos alunos são vistos de uma forma, e uns são taxados como alunos problemas, alguns mais quietos e tímidos e outros nas quais a beleza e o status social são mais importantes. Classes numerosas, baixa remuneração, dificuldades generalizadas com a clientela como disciplina e aprendizagem tem sido um dos principais problemas apontados pelos professores em sala de aula (KHOURI, 1984). Ademais os alunos questionaram a forma a qual esses profissionais da educação ministram o conteúdo em sala e como alguns não conseguem lidar com os problemas da classe. Os alunos falam que falta mais diálogo entre eles e os professores.

Segundo Neves e Damiani (2006), um sujeito ativo no processo educacional dele participa de todas as formas possíveis, questionando e esclarecendo dúvidas, uma vez que o professor se torna um mediador para seu processo de aprendizagem que traz inovações para sala de aula. Os adolescentes participantes evidenciaram que apreciam uma metodologia criativa e que os fazem falar sobre os mais variados assuntos, podendo assim escutar a opinião dos colegas com quem convive diariamente sobre determinado assunto e descobrir assim, pontos em comum e interessantes para rodas de conversas e afins.

Com a chegada de novos avanços tecnológicos, Aberastury e Knobel (1981) citam que o adolescente sente que é o maior responsável por planejar a sua vida, controlar as mudanças pelas quais ele irá passar e assim se adaptar ou não gerando reformas sociais. O programa onde adolescentes são inseridos no mercado de trabalho conhecido como "Adolescentes aprendizes" não ficou de fora, os alunos revelaram interesse em participar e objetivamente adentrar no mercado para assim melhorarem de vida.

$\mathrm{Na}$ escola da rede privada, os alunos demonstravam curiosidade a respeito de vários temas e ressaltaram a vontade de falar sobre eles na escola, além de acreditarem em crenças como a de "não existir falta de informação", já que isso não se aplicava a realidade deles. Apesar

Periódico Horizontes - USF - Itatiba, SP-Brasil - e019010 
de terem condições sociais melhores do que outros alunos, esses jovens relataram a necessidade de estar mais próximo a profissionais que os ajudem a encontrar respostas às muitas perguntas que possuíam. Rappaport; Fiorri e Davis (1981-1982) relata que os jovens repensam nos mistérios e problemas que surgem e lutam bravamente para achar uma resposta adequada a eles, questionando sempre a si próprio e em busca de um papel para si mesmo.

Em geral, nos depoimentos dos alunos participantes, nota-se que os fatores externos nos quais cada um está exposto em sua realidade acabam interferindo na visão que esses adolescentes fazem da escola, pois os mesmos descrevem que problemas familiares, na maior parte do tempo, afetam não somente seu comportamento em sala de aula como também em seu desempenho. Muitos também relataram não acreditarem que através da escola se pode chegar a uma vida melhor e até mesmo a realizar seus sonhos uma vez experienciando a profissão a que deseje.

\section{Conclusão}

Por meio deste trabalho foi possível entrar em contato com a dinâmica escolar das escolas participantes, além de ouvir dos seus alunos as concepções a respeito da própria escola e o que os mesmos pensam daqui para frente. Foram identificados os fatores que ajudam em uma construção errônea a respeito desse lugar e da importância na vida do indivíduo, pois a mesma torna-se o passo inicial para a construção do futuro do adolescente.

Apesar das interferências externas e das crenças que cada adolescente carrega dentro de si, o trabalho propiciou uma reflexão para esses jovens, fazendo com que os mesmos repensem nas decisões e comportamentos assim planejarem a carreira que almejam.

Dar voz a esses adolescentes a realizarem discussões acerca das questões pertinentes ao âmbito escolar fortalece não apenas os vínculos entre profissionais e alunos, isso auxilia na promoção e prevenção de saúde, uma vez que esses sujeitos se tornam protagonistas das suas histórias compreendendo melhor sua realidade estando munido de informações que possam transformá-las como a si mesmo. Desse modo, a escola passa a ser um âmbito seguro e que, também, favoreça o crescimento saudável dos jovens, promovendo a construção de cidadãos 
éticos e políticos para que cada um possa se posicionar diante das barreiras existentes na sociedade.

\section{Referências}

ABERASTURY, A. KNOBEL, M. Adolescência normal: um enfoque psicanalítico. Trad. S. M. G. Ballve. 1a Ed. Porto Alegre: Artes Médicas, 1981.

ANDRARA, E. G. C. Novos paradigmas na prática do psicólogo escolar. Revista Psicologia: reflexão e crítica, v.18, p.196-199, 2005.

ATKINSON \& HILGARD. Introdução à psicologia. 15. ed. São Paulo: Cengage Learning, 2012.

BOCK, A. M. M. B; FURTADO, O; TEIXEIRA, M. L. T. Psicologias: uma introdução ao estudo de psicologia, 14 ed. São Paulo: Saraiva, 2008.

BRASIL. Instituto Nacional de Estudos e Pesquisas Educacionais Anísio Teixeira. Educacenso: Censo Escolar da Educação Básica. Brasília, 2009.

BRASIL. Instituto Brasileiro de Geografia e Estatística. Pesquisa nacional por amostra de domicílios, 2010. Rio de Janeiro.

BRASIL. Lei no 12.796/2013, de 04 de abril de 2013, atualiza o Estatuto da Criança e do Adolescente: Lei no 8.069, de 13 de julho de 1990. novembro de 2013. Paraná.

CLERGET, S. Adolescência: a crise necessária. Trad. M. A. Villela. $1^{\circ}$ Ed. Rio de Janeiro: Rocco, 2004.

CONTINI, M. L. J. Adolescência e psicologia: concepções, práticas e reflexões críticas. Dados Eletrônicos - Rio de Janeiro: Conselho Federal de Psicologia, 2002.

DAYRELL, J. T. Juventude e escola. In: SPOSITO, M. (Org.). O estado da arte sobre juventude na pós graduação brasileira: educação, ciências sociais e serviço social (1999-2006). Belo Horizonte: Argumentum, 2009. p. 57-126.

FERREIRA, A. B. H. Mini Aurélio século XXI escolar: o minidicionário da língua portuguesa. 4. ed. Rio de Janeiro: Nova Fronteira, 2001.

HABIGZANG, L. F.; DINIZ, E.; KOLLER, S. H. Trabalhando com adolescentes: teoria e intervenção psicológica. $1^{\circ} \mathrm{Ed}$. Porto Alegre: Artmed, 2014.

Periódico Horizontes - USF - Itatiba, SP-Brasil - e019010 
KHOURI, Y. G. Psicologia escolar: coleção temas básicos de psicologia, vol. 1. $1^{\circ}$ Ed. São Paulo: EPU, 1984.

LANE, S. T. M. O que é psicologia social. $1^{\circ}$ Ed. - São Paulo : Brasiliense, 1981.

LÍRIO, L. C. A construção histórica da adolescência. In: Congresso Internacional da Faculdades Est, 2012. Anais... v. 1, 2012, p.1675-1688.

NEVES, R. A.; DAMIANI, M. F. Vygotsky e as teorias da aprendizagem. Revista UNIrevista, v. 1, n. 2, p. 1-10, abr. 2006.

PAPALIA, D. E; FELDMAN, R. D. Desenvolvimento humano. Trad. C. F. M. P. Vercesi et al. 12. ed. Porto Alegre: AMGH, 2013.

PATTO, M. H. S. Introdução à psicologia escolar. 3. ed. São Paulo: Casa do Psicólogo, 1997.

RAPPAPORT, C. R; FIORRI, W. R; DAVIS, C. Psicologia do desenvolvimento. vol. 4: a idade escolar e a adolescência. 1. ed. São Paulo: EPU, 1981-1982.

SCHOEN-FERREIRA, T.H; AZNAR-FARIAS, M.; SILVARES, E.F.M; Adolescência através dos séculos. Revista Psicologia: teoria e pesquisa, v.26 n.2, p.227-234, abr./jun. 2010.

TIBA, I. Puberdade e adolescência: desenvolvimento biopsicossocial. 1 ed. São Paulo: Ágora, 1986.

Recebido em dezembro de 2017.

Aprovado em maio de 2018. 